\title{
Structural and Optical Characterization of ZnO Nanoparticles Synthesized by Microemulsion Route
}

\author{
Harish Kumar*, Renu Rani \\ Department of Chemistry, Chaudhary Devi Lal University, Sirsa 125055 (Haryana), India \\ Fax. No. 01666-248123, Ph. 01666-247136 (O) \\ *E-mail address: harimoudgil1@rediffmail.com
}

\begin{abstract}
$\mathrm{ZnO}$ nanoparticles were synthesized by microemulsion route in $\mathrm{W} / \mathrm{S}$ ratio of 5 at room temperature. X-ray diffraction (XRD) pattern reveals wurtzite structure of $\mathrm{ZnO}$ nanoparticles. Rod shape of $\mathrm{ZnO}$ nanoparticles of average particle size 10.0 to $12.0 \mathrm{~nm}$ were observed by transmission electron microscopy. FT-IR spectra confirmed the adsorption of surfactant molecules at the surface of $\mathrm{ZnO}$ nanoparticles and presence of $\mathrm{Zn}-\mathrm{O}$ bonding. Thermal studies were carried out by the differential scanning calorimeter (DSC) techniques. In addition, UV-Visible spectra were employed to estimate the band gap energy of $\mathrm{ZnO}$ nanoparticles.
\end{abstract}

Keywords: Nanostructure; Microemulsion; Powder diffraction; Optical properties

\section{INTRODUCTION}

In recent years, noble metal oxide nanoparticles have been the subject of focused research due to their unique electronic, optical, mechanical, magnetic and chemical properties that are significantly different from those of bulk counterpart ${ }^{1-5}$. Nanostructured $\mathrm{ZnO}$ materials have drawn broad attention due to its wide range of applications in ultraviolet (UV) lasers $^{6}$, power generators ${ }^{7}$, solar cells ${ }^{8}$, gas sensors ${ }^{9}$, field emission devices ${ }^{10}$, capacitors, varistors, transparent UV resistance coating, photoprinting, electrophotography, electrochemical and electromechanical nanodevices, sun screen lotion (cream), cosmetic and medicated creams etc. ${ }^{11-14}$. Zinc oxide $(\mathrm{ZnO})$ is a wide band gap semiconductor with an energy gap of $3.30,3.28$, and $3.27 \mathrm{eV}$ at 300,500 , and $700{ }^{\circ} \mathrm{C}^{15} . \mathrm{ZnO}$ nanocrystals or quantum dots (QDs) have superior optical properties of the bulk crystals owing to quantum confinement effects.

A variety of preparation routes have been reported for the preparation of metal oxide nanoparticle $^{3,4}$ notable examples include, reverse micelles process ${ }^{5,16}$, salt reduction ${ }^{17}$, microwave dielectric heating reduction ${ }^{18}$, ultrasonic irradiation ${ }^{19}$, radiolysis $^{20,21}$, solvothermal synthesis $^{22}$, electrochemical synthesis ${ }^{23,24}$ etc.

Compare to other methods, the reverse micelle method is one of the most promising wet chemistry synthesis approaches of synthesis of metal oxide nanoparticles ${ }^{25}$. This method provides a favorable microenvironment for controlling the chemical reaction. As such the reaction rate can be easily controlled, and it is possible to obtain a narrow nanoparticle size distribution $^{26}$. Reverse micelle microemulsions are transparent, isotropic, and thermodynamically stable ${ }^{27,28}$. 
In continuation to our earlier research work ${ }^{29,30}$, present work reports synthesis of $\mathrm{ZnO}$ nanoparticles by microemulsion route. Characterization of $\mathrm{ZnO}$ nanoparticles were carried out by XRD, TEM, DSC, FTIR and UV-Visible spectroscopy. Emphasis has been given on structural and optical properties of $\mathrm{CuO}$ nanoparticles, etc. ${ }^{50-54}$.

\section{EXPERIMENTAL}

\section{1. Materials and method}

All chemicals used in experiment were of analytical grade. The stable reverse micelle microemulsion was prepared by mixing a non-ionic surfactant, Triton X-100 $\left[\left(\mathrm{C}_{14} \mathrm{H}_{22} \mathrm{O}\left(\mathrm{C}_{2} \mathrm{H}_{4} \mathrm{O}\right)_{\mathrm{n}}\right]\right.$ (Qualigen Chem. Pvt. Ltd., Mumbai), Polyvinyl pyrollidone (PVP) (K85-95) (Merk, India) and 1:9 ratio of cyclohexane (Qualigen Chem. Pvt. Ltd., Mumbai) and triple distilled water (conductivity less than $1 \times 10^{-6} \mathrm{~S} \mathrm{~cm}^{-1}$ ). The microemulsion was mixed rapidly with continuous stirring for five minutes. $\mathrm{ZnSO}_{4} \cdot 6 \mathrm{H}_{2} \mathrm{O}$ (Qualigen Chem. Pvt. Ltd., Mumbai) solution $(0.5 \mathrm{M})$ was added drop by drop to microemulsion with continuous stirring. A sky blue color mixture was obtained. PVP was used as a stabilizing agent. After half an hour of equilibration, 2.0 M hydrazine hydrate (Qualigen Chem. Pvt. Ltd., Mumbai) solution was added drop by drop with continuous stirring at room temperature. The reverse micelles were broken by adding THF (Merk, India).

$\mathrm{ZnO}$ nanoparticles were subsequently washed with ethanol and triple distilled water to remove residual PVP and surfactant molecules. After washing $\mathrm{ZnO}$ nanoparticles were dried in oven at $100.0^{\circ} \mathrm{C}$ for 48 hours.

\section{2. Characterization techniques}

Structural and optical properties of the $\mathrm{ZnO}$ nanoparticles were determined by using Transmission Electron Microscopy (TEM) (Hitachi: H-7500; Resolution: $2 \AA$ ), X-ray Diffraction (XRD) (Rikagu Mini-2 using CuKa1, $\lambda=0.15406 \mathrm{~nm}$ radiations), Differential Scaning Colorimetery (DSC) (TA Instruments USA, DSC Q10) in the range $50-600{ }^{\circ} \mathrm{C}$, Fourier Transform Infra-Red spectroscopy (FTIR) (Thermo-USA, FTIR-380) in the wavelength range of $400-4000 \mathrm{~cm}^{-1}$ and UV-Visible spectroscopy (Systronic-2203).

\section{RESULT AND DESCUSSION}

\section{1. Synthesis}

$\mathrm{ZnSO}_{4} \cdot 7 \mathrm{H}_{2} \mathrm{O}$ crystallizes in the orthorhombic structure. Here six water molecules make a highly distorted octahedron around $\mathrm{Zn}^{+2}$ ion $^{31}$. Due to the solvating action, $\mathrm{ZnSO}_{4} \cdot 7 \mathrm{H}_{2} \mathrm{O}$ dissolves in water to produce the colorless solution which is due to the presence of $\left[\mathrm{Zn}\left(\mathrm{H}_{2} \mathrm{O}\right)_{7}\right]^{2+}$ ions.

Addition of $\mathrm{N}_{2} \mathrm{H}_{4} \cdot \mathrm{H}_{2} \mathrm{O}$ to the aqueous solutions of zinc sulphate heptahydrate results to production of white precipitates of $\mathrm{Zn}$ nanoparticles inside the miceller core. PVP act as stabilizer for these $\mathrm{Zn}$ nanoparticles. The surfactant and PVP molecules adhere to the surface of nanoparticles which serve as a protective layer to prevent the further reaction. The $\mathrm{Zn}$ nanoparticles are oxidized into $\mathrm{ZnO}$ nanoparticles in the presence of atmospheric oxygen at $100{ }^{\circ} \mathrm{C}$.

The reaction profile of formation $\mathrm{ZnO}$ nanoparticles can be illustrated as:

(1) $\mathrm{ZnSO}_{4}(\mathrm{aq})+\mathrm{N}_{2} \mathrm{H}_{4}+2 \mathrm{H}_{2} \mathrm{O}(\mathrm{l}) \rightarrow 2 \mathrm{Zn}(\mathrm{s})+2\left(\mathrm{~N}_{2} \mathrm{H}_{5}\right) \mathrm{SO}_{4}(\mathrm{aq})+\mathrm{O}_{2}$

(2) $2 \mathrm{Zn}(\mathrm{s})+\mathrm{O}_{2} \rightarrow 2 \mathrm{ZnO}(\mathrm{s})$ 
There are two important factors that affect the exchange rate of reverse micelles in microemulsions; the stability of the dimer form and the size of channels between the two dimers $^{32}$. The dimer stability, which depends on the intermicellar attractive potential, determines the interdroplet transfer of reactants. On the other hand, the size of channels which depends on the rigidity of interfacial film in the microemulsion, determines the Ostwald ripening contribution $^{33}$.

\section{2. X-ray diffraction analysis}

Figure 1 shows XRD diffraction pattern of $\mathrm{ZnO}$ nanoparticles. The peaks are indexed as $31.82^{\circ}(100), 34.54^{\circ}(002), 36.42^{\circ}(101), 47.46^{\circ}(102), 56.74^{\circ}(110), 62.92^{\circ}(103), 66.06^{\circ}$ (200), $68.42^{\circ}(112), 69.06^{\circ}(201)$ and $78.82^{\circ}$ (202) respectively. All diffraction peaks of sample correspond to the characteristic hexagonal wurtzite structure of zinc oxide nanoparticles $(\mathrm{a}=0.315 \mathrm{~nm} \text { and } \mathrm{c}=0.529 \mathrm{~nm})^{34}$. Similar, X-ray diffraction pattern were reported by $\mathrm{C}$. Chen et. al. ${ }^{35}$ and $\mathrm{Y}$. Pong et. al. ${ }^{36}$. Average particle size of $\mathrm{ZnO}$ nanoparticles is found to be $10.0 \mathrm{~nm}$ using Scherrer equation ${ }^{37}$. Diffraction pattern corresponding to impurities are found to be absent. This proves that pure $\mathrm{ZnO}$ nanoparticles were as synthesized.

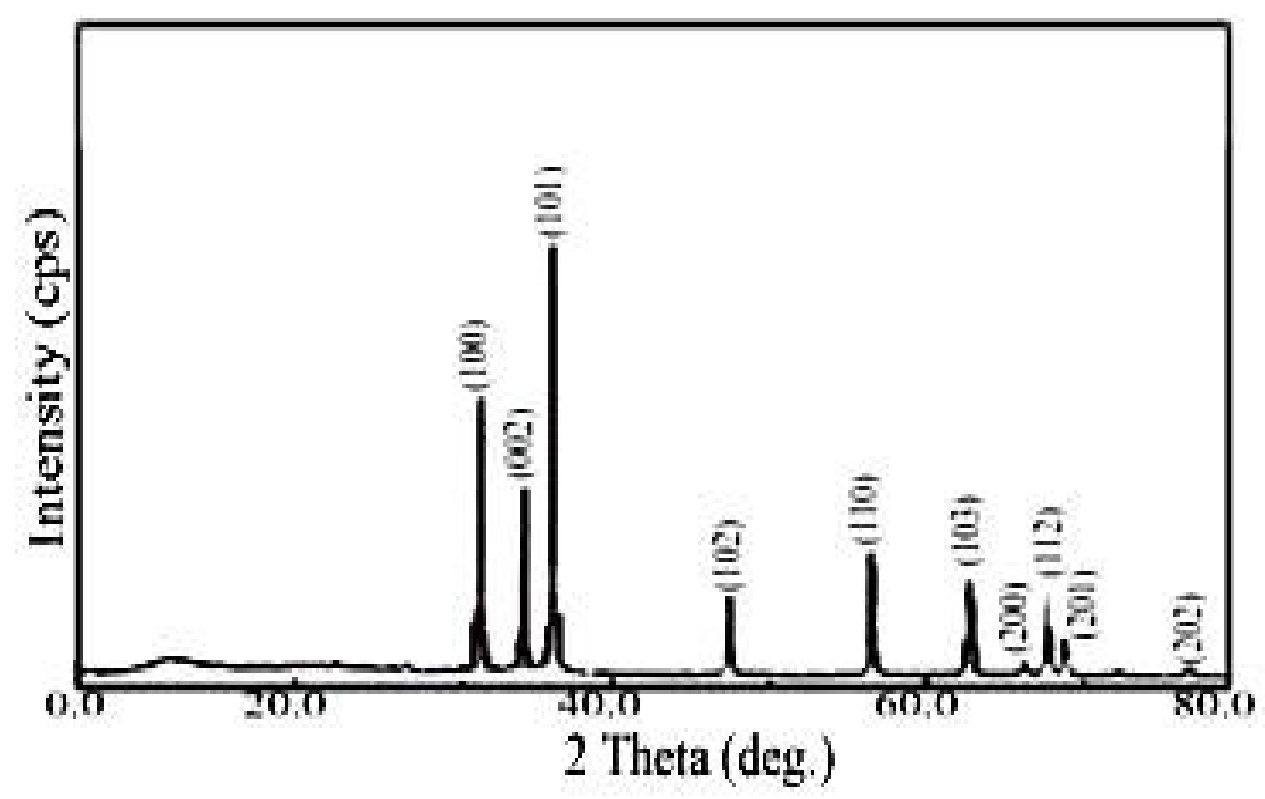

Fig. 1. XRD patterns of $\mathrm{ZnO}$ nanoparticle.

\section{3. Transmission Electron Microscopy}

Figure $2(\mathrm{a} \& \mathrm{~b})$ show the TEM images of $\mathrm{ZnO}$ nanoparticles. Rod shape $\mathrm{ZnO}$ nanoparticles were observed in TEM images of average size in the range of 10.0-12.0 nm which is in the good agreement with the size calculated by XRD. Figure 2 (c) shows the selected area diffraction pattern (SAED) of $\mathrm{ZnO}$ nanoparticles. It shows that the particles are well crystallized. The diffraction rings on SAED image matches with the peaks in XRD pattern which also proves the hexagonal wurtzite structure of $\mathrm{ZnO}$ nanoparticles ${ }^{38}$. 

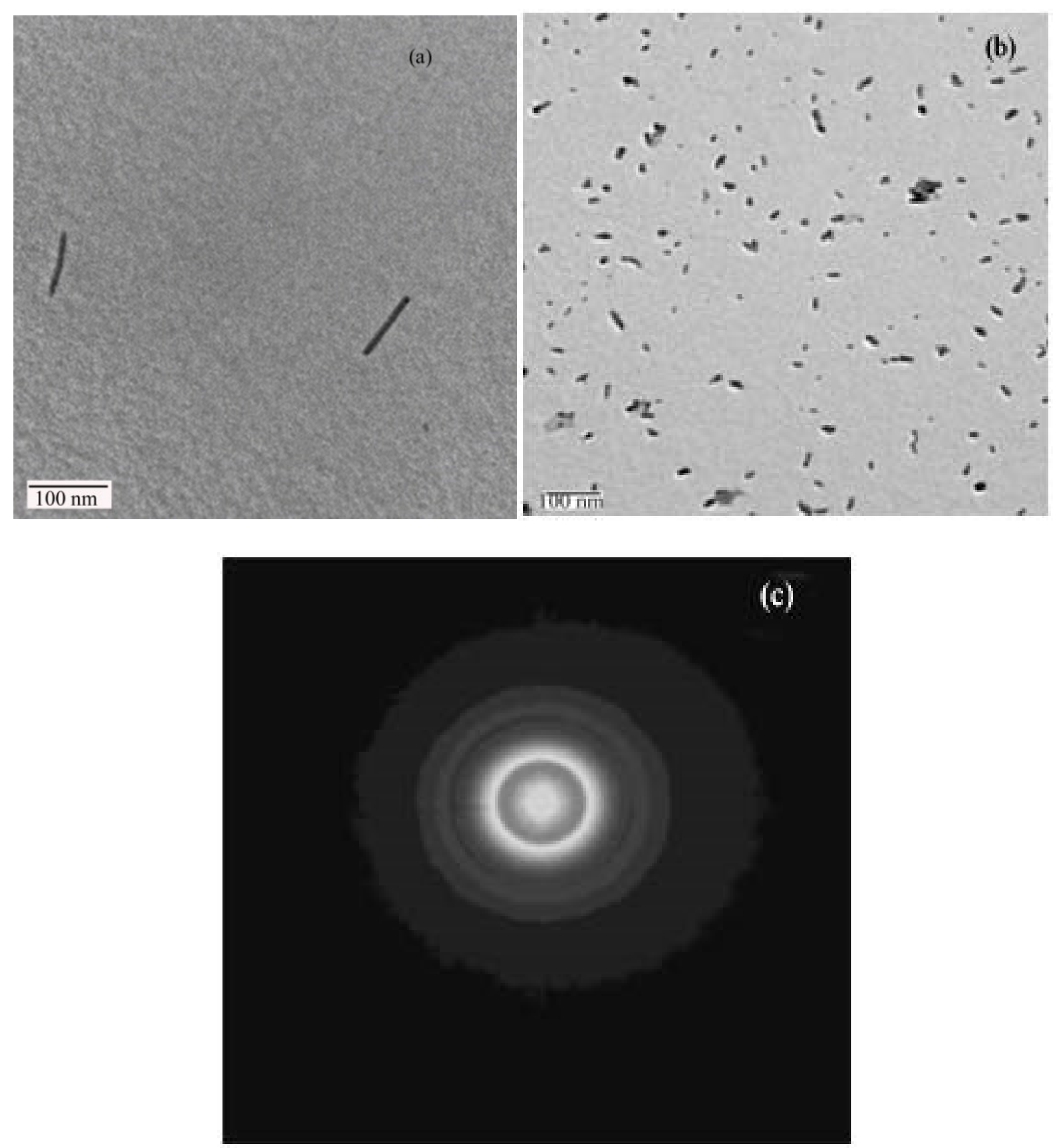

Fig. 2. TEM images of $\mathrm{ZnO}$ nanoparticles $(\mathrm{a}, \mathrm{b})$ and its selected area electron diffraction image (c).

\section{4. FTIR spectroscopy}

Figure 3 shows FTIR spectra of $\mathrm{ZnO}$ nanoparticles. Infrared studies were carried out in order to ascertain the purity and nature of the metal nanoparticles. Metal oxides generally give absorption bands in fingerprint region i.e. below $1000 \mathrm{~cm}^{-1}$ arising from inter-atomic vibrations. The peak observed at 3452.30 and $1119.15 \mathrm{~cm}^{-1}$ are may be due to O-H stretching and deformation, respectively assigned to the water adsorption on the metal surface. The peaks at $1634.00,620.93 \mathrm{~cm}^{-1}$ are correspond to $\mathrm{Zn}-\mathrm{O}$ stretching and deformation vibration, respectively. The metal-oxygen frequencies observed for the respective metal oxides are in accordance with literature values ${ }^{39,40}$. V. Parthasarathi and G. Thilagavathi ${ }^{41}$ reported similar FTIR spectra observed of zinc oxide nanoparticles in their investigation. 


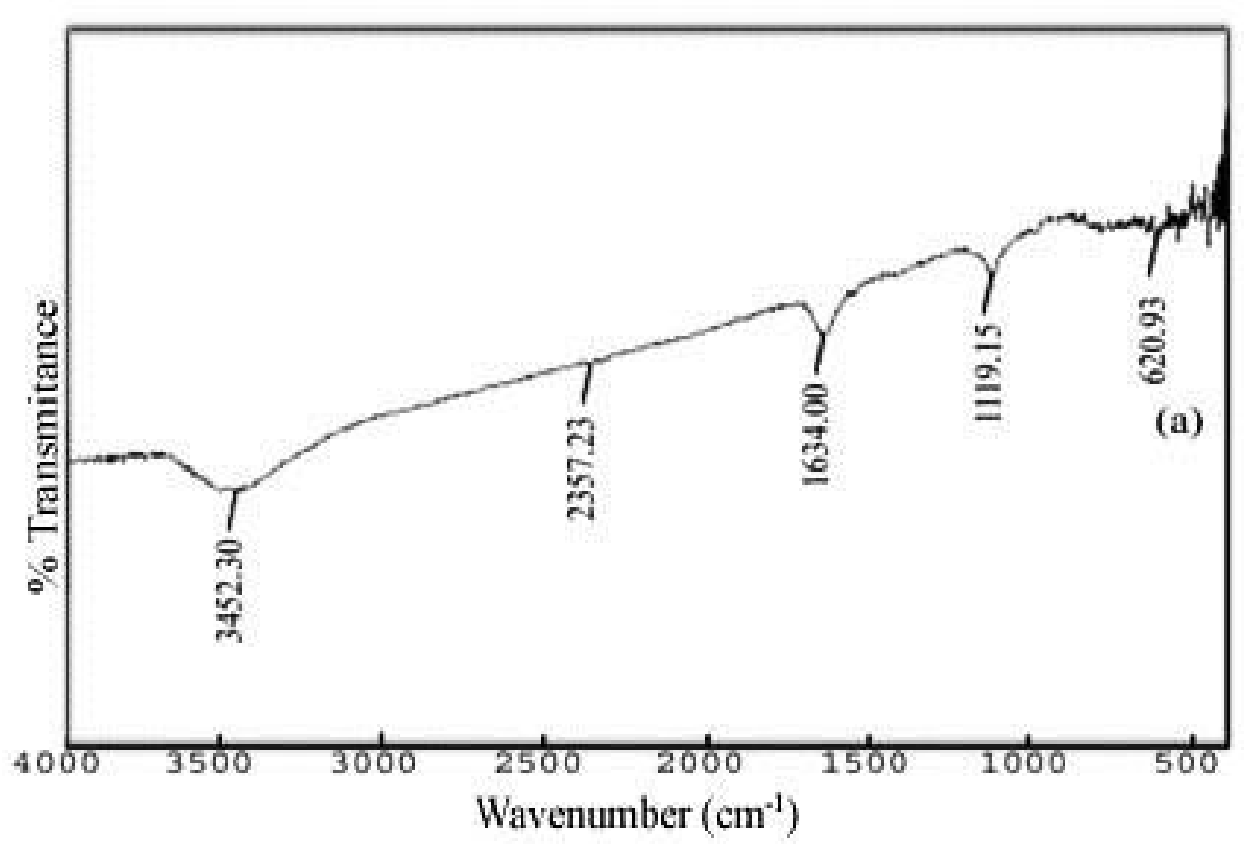

Fig. 3. FTIR spectra of $\mathrm{ZnO}$ nanoparticles.

\section{5. UV-Visible spectroscopy}

The optical characterization of the sample was recorded on UV-Vis absorption spectrophotometer Figure 4 (a) shows the UV-Visible absorption spectra of $\mathrm{ZnO}$ nanoparticles as a function of wavelength. The UV-Visible absorption spectroscopy of $\mathrm{ZnO}$ nanoparticles in ethanol solvent shows an excitonic absorption peak at about $214 \mathrm{~nm}$, which lies much below the band gap wavelength of $388 \mathrm{~nm}$ of bulk $\mathrm{ZnO}^{42}$. The peak at $214 \mathrm{~nm}$ is due to interband transition of copper electron from deep level of valence band. The blue shift in the peak centered at $\sim 214 \mathrm{~nm}$ in absorption spectra (Figure 4 a) may be due to the transition of electrons from the more inner shell of copper to the uppermost shell as time passes. It is possible that, due to aggregation and agglomeration, particle size increases and material settled down on the bottom of container causing decrease in the absorbance ${ }^{43}$. This behavior is typical for many semiconductors due to internal electric fields within the crystal and inelastic scattering of charge carriers by phonons ${ }^{44,45}$.

Absorption coefficient $(\alpha)$ associated with the strong absorption region of the sample was calculated from absorbent (A) and the sample thickness (t) was used the relation: 


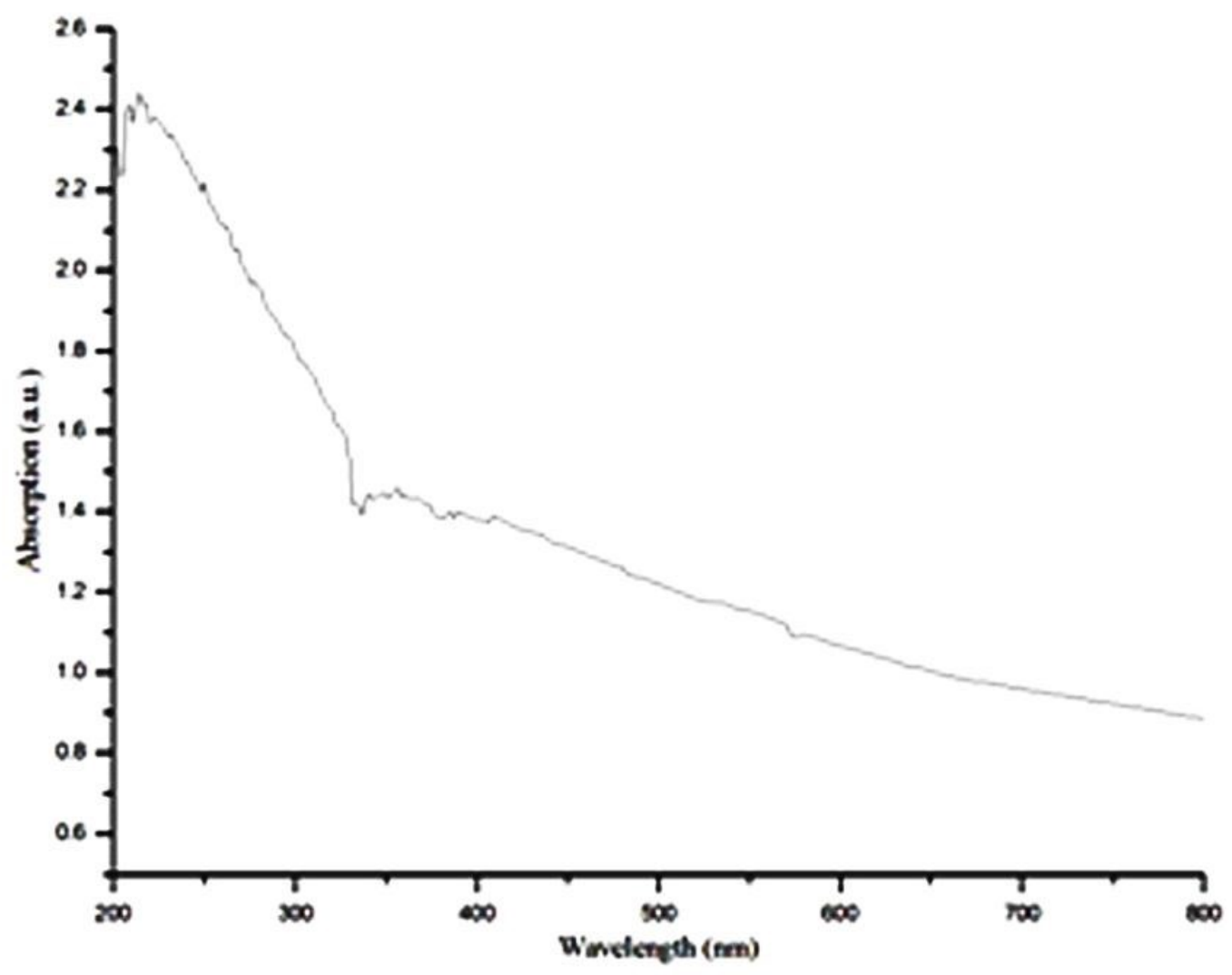

Fig. 4(a). Absorption of $\mathrm{ZnO}$ nanoparticles as a function of wavelength.

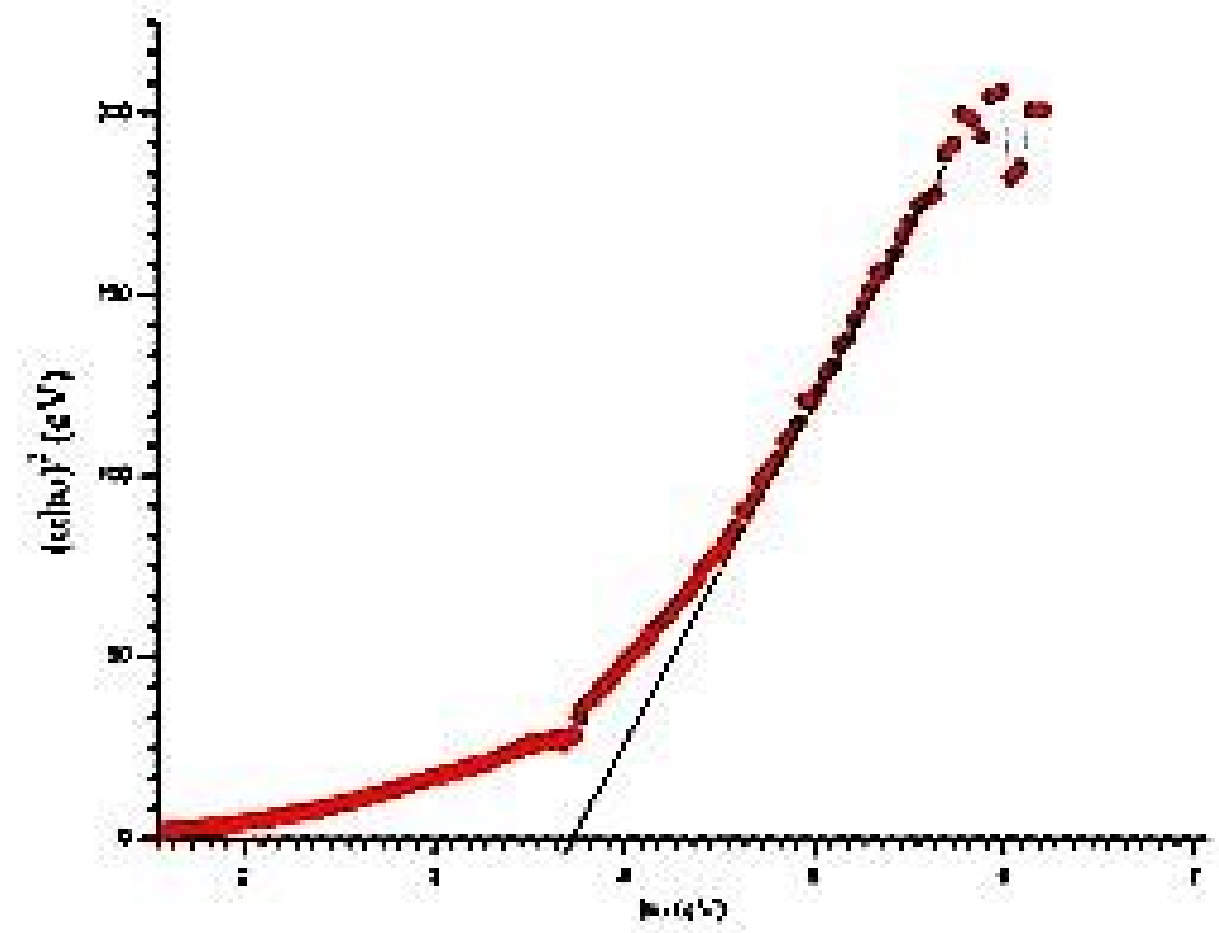

Fig. 4(b). Variation of $(\alpha h v)^{2}$ with $h v$ for $\mathrm{ZnO}$ nanoparticles as a function of wavelength at $n$ value of $1 / 2$.

$$
\alpha=2.303 \mathrm{~A} / \mathrm{t}
$$


While the optical band gap of $\mathrm{ZnO}$ nanoparticles is calculated using the Tauc relation ${ }^{46}$ :

$$
\alpha=\frac{B\left(h v-E_{g}\right)^{n}}{h v}
$$

Where, $\alpha$ is the absorption coefficient, $B$ is a constant, $h v$ is the energy of incident photons and exponents $n$ whose value depends upon the type the transition which may have values $1 / 2,2,3 / 2$ and 3 corresponding to the allowed direct, allowed indirect, forbidden direct and forbidden indirect transitions, respectively ${ }^{47}$. Figure 4 (b) show the variation of $(\alpha$ $h v)^{1 / \mathrm{n}}$ vs. photon energy, $h v$ for $\mathrm{ZnO}$ nanoparticles with $\mathrm{n}$ values of $1 / 2$. Allowed direct band gap of $\mathrm{ZnO}$ nanoparticles is calculated to be $3.7 \mathrm{eV}$, which is higher than reported value $3.53^{48} \mathrm{eV}$. The increase in the band gap of the $\mathrm{ZnO}$ nanoparticles with the decrease in particle size may be due to a quantum confinement effect ${ }^{49}$.

\section{6. DSC analysis}

The isothermal oxidation behavior and the oxidized structure of $\mathrm{ZnO}$ nanoparticles have been investigated using DSC technique over a temperature range of $50-600{ }^{\circ} \mathrm{C}$ in ambient air. Figure 5 shows DSC curve of zinc oxide nanoparticles. A small low temperature endothermic peak at $138.81{ }^{\circ} \mathrm{C}$ is due to loss of volatile surfactant molecule adsorbed on the surface of zinc oxide nanoparticles during synthesis conditions. A large high temperature endothermic peak at $260.43{ }^{\circ} \mathrm{C}$ is assigned the conversion of zinc hydroxide to zinc oxide nanoparticles. A small high temperature endothermic peak at $382.77{ }^{\circ} \mathrm{C}$ attributed the conversion of zinc oxide into zinc nanoparticles.

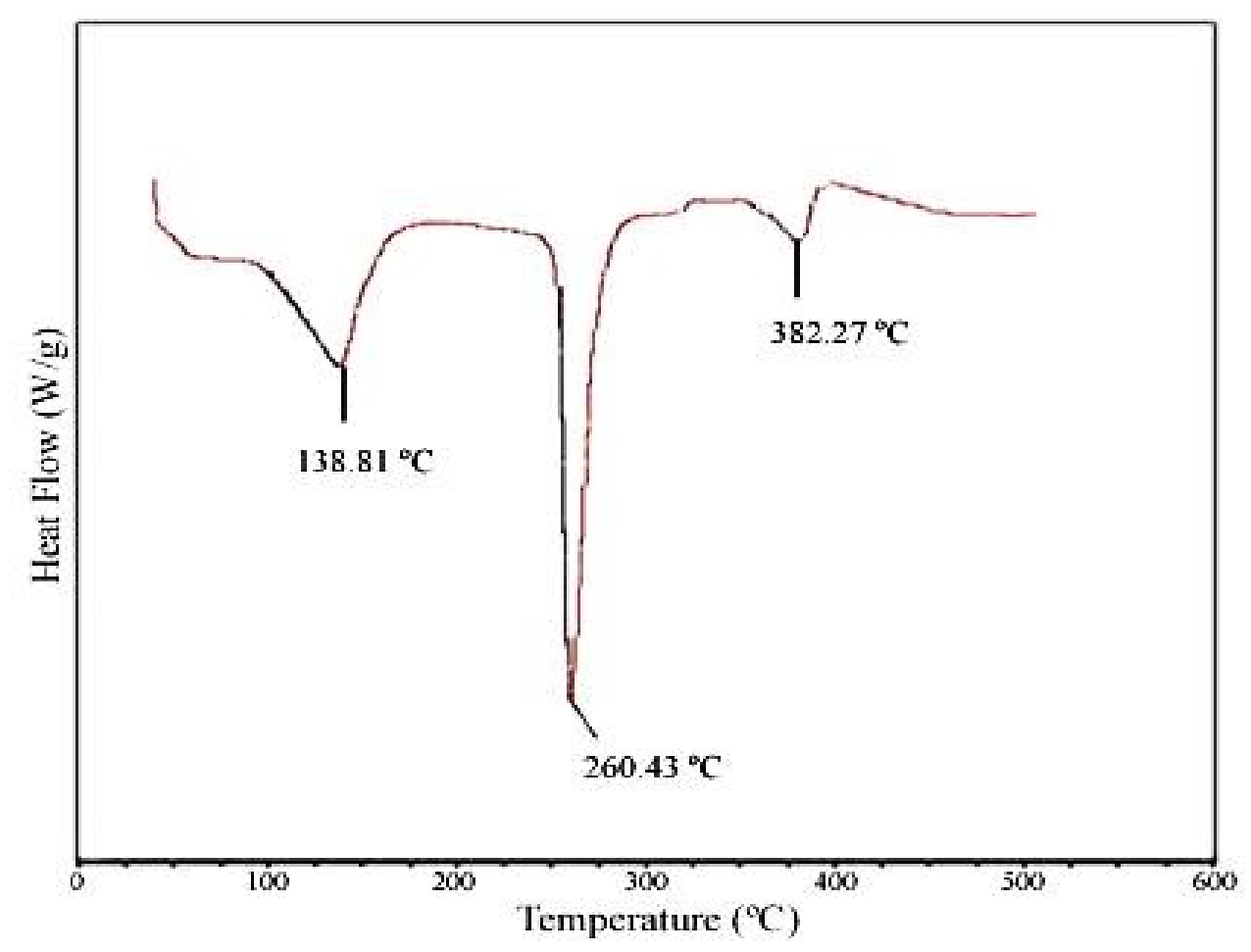

Fig. 5 DSC curve of ZnO nanoparticles. 


\section{CONCLUSION}

$\mathrm{ZnO}$ nanoparticles of hexagonal wurtzite structure are synthesized by microemulsion technique. From TEM study, it is found that $\mathrm{ZnO}$ nanoparticles are of rod shape with average size of 10.0-12.0 nm. The FTIR spectral analysis reveals the characterstics peaks for Zn-O stretching. The absorption of water molecules on the $\mathrm{ZnO}$ nanoparticles is confirmed by FTIR spectra. The UV-Visible study shows blue shift absorption at $\sim 214 \mathrm{~nm}$. Allowed direct band gap energy of $\mathrm{ZnO}$ nanoparticles are found to be higher as compared to their bulk counter part. Thermal studies are carried out by DSC technique which further confirms the formation of $\mathrm{ZnO}$ nanoparticles.

\section{References}

[1] Maciej Mazur, Electrochemistry Communications 6 (2004) 400-403.

[2] Lili Feng, Chunlei Zhang, Guo Gao, Daxiang Cui, Nanoscale Research Letters 7 (2012) 1-10.

[3] Angshuman Pal, Sunil Shah, Surekha Devi, Colloids and Surfaces A Physicochemical and Engineering Aspects 302 (2007) 483-487.

[4] M. J. Rosemary, Thalappil Pradeep, Colloids and Surfaces A Physicochemical and Engineering Aspects A 268 (2003) 81-84.

[5] Yingwei Xie, Ruqiang Ye, Honglai Liu, Colloids and Surfaces A Physicochemical and Engineering Aspects 279 (2006) 175-178.

[6] Michael H. Huang, Samuel Mao, Henning Feick, Haoquan Yan, Yiying Wu, Hannes Kind, Eicke Weber, Richard Russo, Peidong Yang, Science 292 (2001) 1897-1899.

[7] Xudong Wang, Jinhui Song, Jin Liu, Zhang L. Wang, Science 316 (2007) 102-105.

[8] C. Y. Jiang, X. W. Sun, G. Q. Lo, D. L. Kwong, J. X. Wang, Applied Physics Letters 90 (2007) 263501-263503.

[9] Qing Wan, Q. H. Li, Y. J. Chen, Ta-Hung Wang, X. L. He, J. P. Li, C. L. Lin, Applied Physics Letters 84 (2004) 3654-3656.

[10] Chia Ying Lee, Seu Yi Li, Pang Lin, Tseung-Yuen Tseng, Journal of Nanoscience Nanotechnology 5 (2005) 1088-1094.

[11] Hung-Ta Wang, B. S. Kang, Fan Ren, L. C. Tien, P. W. Sadik, D. P. Norton, S. J. Pearton, J. Lin, Applied Physics Letters 86 (2005) 243503-243505.

[12] Jih-Jen Wu, Guan-Ren Chen, Hung-Hsien Yang, Chen-Hao Ku, Jr-Yuan Lai, Applied Physics Letters 90 (2007) 213109-213111.

[13] S. F. Yu, C. Yuen, S. P. Lau, W. I. Park, G. C. Yi, Applied Physics Letters 84 (2004) 3241-3243.

[14] Nick Serpone, Deniele Dondi, Angelo Albini, Inorganica Chimica Acta 360 (2007) 794-802.

[15] Surabhi S. Kumar, Putcha Venkateswarlu, Vanka. R. Rao, Gollapalli N. Rao, International Nano Letters 3 (2013) 1-6.

[16] M. Maillard, S. Giorgo, Marie P. Pileni, Advanced Material 14 (2002)1084-1086. 
[17] Zeena S. Pillai, Prashant V. Kamat, The Journal of Physical Chemistry B 108 (2004) 945-951.

[18] Kirti Patel, Sudhir Kapoor, D. P. Dave, Tulsi Murherjee, Journal of Chemical Science 117 (2005) 53-60.

[19] R. A. Salkar, P. Jeevanandam, S. T. Aruna, Yuri Koltypin, A. Gedanken, Journal of Materials Chemistry 9 (1999) 1333-1335.

[20] Behrouz Soroushian, Isabelle Lampre, Jacqueline Belloni, Mehran Mostafavi, Radiation Physics Chemistry 72 (2005) 111-118.

[21] B. G. Ershov, E. Janata, A. Henglein, A. Fojtik, Unpubliseh report (2007).

[22] Maria Starowicz, Barbara Stypula, Jacek Banaœ, Electrochemistry Communications 8 (2006) 227-230.

[23] Jun-Jie Zhu, Xue-Hong Liao, Xiao-Ning Zhao, Hong-Yuang Hen, Material Letters 49 (2001) 91-95.

[24] S. Liu, S. Chen, S. Avivi, A. Gendanken, Journal of Non-crystalline Solids 283 (2001) 231-236.

[25] F. J. Arriagada, K. Osseo-Asare, Journal of Colloid Interface Science 211 (1999) 210220.

[26] Dong-Sik Bae, Eun-Jung Jungkim, Jae-Hee Bang, Sang-Woo Kim, Kyong-Sop Han, Jong-Kyu Lee, Byang-Ik Kim, James H. Adair, Metal and Materials International 11 (2005) 291-294.

[27] Dong-Sik Bae, Sang-Whan Park, Kyon-Sop Han, James H. Adair, Metal and Materials International 7 (2001) 399-402.

[28] Marei P. Pileni, Structure and reactivity in reverse micelles, Elsevier, Amsterdam, New York (1989).

[29] Harish Kumar, Renu Rani, Raj K. Salar, The European conference of chemical engineering, and European conference of civil engineering, and European conference of mechanical engineering, and European conference on Control (ECCE-10), 30 Nov.2 Dec., 2010, Tennrife Insland, Spain 88-94.

[30] Harish Kumar, Renu Rani, Raj K. Salar, Research Journal of Chemical 1 (2011) 42-48.

[31] J. K. Saha, J. Podder, Journal of Bangladesh Academic Sciences 35 (2011) 203-21.

[32] S. Quintillán, C. Tojo, M. C. Blanco, M. A. López-Quintela, Langmiur 17 (2001) 72517254.

[33] D. Dodoo-Arhin, M. Leoni, P. Scardi, Molecular Crystals \& Liquid Crystals 555 (2012) 17-31. 
[34] Joint Committee on powder diffraction standards (2000) Diffraction data file, No. 361451.

[35] C. Chena, B. Yu, P. Liu, J. F. Liu, L. Wang, Journal of Ceramic Processing Research 12 (2011) 420-425.

[36] Swee-Yong Pung, Wen-Pie Lee, Azizan Aziz, International Journal of Inorganic Chemistry 2012 (2012) 1-9.

[37] B. D. Culity, Elements of X-ray diffraction $2^{\text {nd }}$ ed, Addison-Wesley, USA, 1987

[38] G. Voicu, O. Oprea, B. S. Vasile, E. Andronescu, Digest Journal of Nanomaterials and Biostructures 8 (2013) 667-675.

[39] C. N. R. Rao, Chemical Applications of Infrared spectroscopy, Academic Press, New York and London, 1963.

[40] I. Markova-Deneva, Journal of the University of Chemical Technology and Metallurgy 45 (2010) 351-378.

[41] V. Parthasarathi, G. Thilagavathi, International Journal of Pharmaceutical Science 3 (2012) 1-7.

[42] Pathik Kumbhakar, Devendra Singh, Chandra S. Tiwary, Amya K. Mitra, Chalcogenide letters 5 (2008) 387-394.

[43] T. S. Moss, G. J. Burrell, B. Ellis, Semiconductor Opto-Electronics, Butterworth \& Co. Ltd. 1973.

[44] H. M. Honsi, S. A. Fayek, S. M. Al-Sayed, M. Roushdy, M. A. Soliman, Vacuum 81 (2006) 54-58.

[45] A. Sawby, M. S. Selim, S. Y. Marzouk, M. A. Mostafa, A. Hosny, Physica B: Physics of Condensed Matter 405 (2010) 3412-3420.

[46] N. F. Mott, E. A. Davies, Electronic Processes in Non-Crystalline Materials, $2^{\text {nd }}$ ed., Claredon Press, Oxford, 1979.

[47] A. N. Banerjee, K. K. Chattopadhyay, in D. Depla, S. Maheiu (Eds.), SpringerVerlag: Berlin, Heidelberg, 2008.

[48] M. Mazhdi, P. Hossein Khani, International Journal of Nano Dimensions 2 (2012) 233240.

[49] J. P. Yang,, F. C. Meldrum, J. H. Fendler, Journal of Physical Chemistry 99 (1995), 5500-5504.

[50] Saad F. Oboudi, Nadir F. Habubi, Ghuson H. Mohamed, Sami S. Chiad, International Letters of Chemistry, Physics and Astronomy 8(1) (2013) 78-86.

[51] Sujan Kumar Das, Jahid M. M. Islam, Monirul Hasan, Humayun Kabir, Md. Abdul Gafur, Enamul Hoque, Mubarak A. Khan, International Letters of Chemistry, Physics and Astronomy 10(1) (2013) 90-101. 
[52] J. A. Najim, J. M. Rozaiq, International Letters of Chemistry, Physics and Astronomy 10(2) (2013) 137-150.

[53] Majid H. Hassouni, Khudheir A. Mishjil, Sami S. Chiad, Nadir F. Habubi, International Letters of Chemistry, Physics and Astronomy 11 (2013) 26-37.

[54] C. Indira Priyadharsini, A. Prakasam, P. M. Anbarasan, International Letters of Chemistry, Physics and Astronomy 12 (2013) 82-93

( Received 13 September 2013; accepted 17 September 2013 ) 